\title{
Invorderingswet 1990
}

Mr. Drs. K. E. Koppenol

\section{Inleiding}

Op 1 juni 1990 is de Invorderingswet 1990 in werking getreden. De wet vervangt de Invorderingswet 1845 en brengt invorderingsbepalingen, die eerst verspreid waren over 54 verschillende wetten, samen. Zij geldt voor alle rijksbelastingen behalve de invoerrechten en accijnzen.

Uitgangspunten van de wet zijn:

- een versterking van de positie van de ontvanger;

- een vergroting van de doelmatigheid van het invorderingsproces;

- een versterking van de rechtspositie van de belastingschuldigen en de aansprakelijkgestelden.

Ook zijn op 1 juni 1990 het Uitvoeringsbesluit Invorderingswet 1990, de Uitvoeringsregeling Invorderingswet 1990, de Invoeringswet Invorderingswet 1990, de Overgansgregeling Invorderingswet 1990 en de Leidraad Invordering 1990 in werking getreden. Met het wijzigen van de Invorderingswet is niet gewacht op de invoering van de boeken 3, 5 en 6 van het Nieuw Burgerlijk Wetboek per 1 januari 1992. Aanpassing van de Invorderingswet 1990 aan met name boek 3 zal nog moeten plaatsvinden. De wijzigingen zullen naar verwachting technisch-juridisch van aard zijn en betrekking hebben op terminologie en systematiek. In dit artikel zal ik de belangrijkste bepalingen van de nieuwe wet bespreken. Hierbij worden de opvallendste wijzigingen ten opzichte van de Invorderingswet 1845 vermeld.

\section{Invordering in eerste aanleg}

In hoofdstuk II van de nieuwe wet is de invorde- ring in eerste aanleg geregeld. De eerste daad van invordering is de ter post bezorging of uitreiking van een aanslagbiljet aan de belastingschuldige door de ontvanger. Een belastingaanslag is in zijn geheel verschuldigd door de belastingschuldige (artikel 8). In beginsel zijn aanslagen pas na het verstrijken van een bepaalde termijn invorderbaar. In artikel 9 zijn de betalingstermijnen, die eerst verspreid waren over verschillende wetten, bijeengebracht. De termijnen zijn:

- in beginsel twee maanden voor een voorlopige aanslag en een aanslag. Lid 4 geeft een afwijkende regeling voor onder andere voorlopige aanslagen inkomstenbelasting en vennootschapsbelasting over het lopende jaar;

- één maand voor een navorderingsaanslag;

- veertien dagen voor een naheffingsaanslag.

In artikel 10 is bepaald dat een aanslag in de volgende gevallen direct invorderbaar is:

a de belastingschuldige is in staat van faillissement verklaard;

$b$ de ontvanger maakt ten genoege van de belastingschuldige aannemelijk dat gegronde vrees bestaat dat goederen van de belastingschuldige zullen worden verduisterd;

c de belastingschuldige wil Nederland metterwoon verlaten dan wel zijn plaats van vestiging overbrengen naar een plaats buiten Nederland, tenzij de belastingschuldige aan de ontvanger aannemelijk maakt dat de belastingschuld wel kan worden verhaald;

$\mathrm{d}$ de belastingschuldige woont of is gevestigd buiten Nederland dan wel heeft in Nederland

Mr. Drs. K. E. Koppenol studeerde Economie en Nederlands Recht aan de Erasmus Universiteit Rotterdam en volgde de post doctorale opleiding tot belastinginspecteur aan de Rijksuniversiteit Leiden. Zij is vanaf 1980 in dienst van het ministerie van Financiën. 


\section{MAB}

geen vaste woonplaats of plaats van vestiging en de ontvanger maakt ten genoege van de belastingschuldige aannemelijk dat gegronde vrees bestaat dat de belastingschuld niet kan worden verhaald;

e er is door de ontvanger beslag gelegd op goederen voor een belastingschuld;

$f$ er worden goederen van de belastingschuldige verkocht ten gevolge van een beslaglegging namens derden;

$\mathrm{g}$ er wordt ten laste van de belastingschuldige een vordering gedaan als is bedoeld in artikel 19 (vereenvoudigd derdenbeslag), tenzij de belastingschuldige aan de ontvanger aannemelijk maakt dat de belastingschuld kan worden verhaald.

\section{Dwanginvordering}

In hoofdstuk III is de dwanginvordering geregeld. Dwanginvordering komt aan de orde indien de belastingschuldige de aanslag niet binnen de gestelde termijn betaalt. In geval van niet-betaling zal de ontvanger eerst een aanmaning (artikel 11) verzenden om alsnog binnen tien dagen na dagtekening van de aanmaning te betalen. Is er na afloop van die termijn nog steeds niet betaald, dan kan de invordering geschieden bij een door de ontvanger uit te vaardigen dwangbevel (artikel 12). Dit dwangbevel brengt mee dat op de roerende en onroerende goederen van de belastingschuldige zonder vonnis van de rechter beslag kan worden gelegd. In hoofdstuk III, artikel 14 Leidraad - dit is de handleiding bij de invordering voor de ambtenaren van de Belastingdienst gegeven door de staatssecretaris van Financiën komen de volgende beslagen aan de orde:

- beslag op roerende goederen;

- beslag op onroerend goed;

- beslag onder derden;

- beslag op schepen.

In paragraaf 1 van artikel 14 Leidraad wordt uiteengezet dat het vooral om praktische redenen doorgaans de voorkeur zal verdienen de tenuitvoerlegging aanvankelijk uitsluitend te richten op verhaal op roerende goederen. Dit neemt echter niet weg, dat bij een belastingschuld van vol- doende grootte andere executoriale maatregelen, zoals inbeslagneming van onroerend goed, reeds aanstonds aan de orde kunnen komen indien het belang van de invordering daardoor is gediend.

Het beslag kan gevolgd worden door openbare verkoop van de beslagen goederen. Zowel de aanmaning als het dwangbevel kan betrekking hebben op verschillende belastingaanslagen. Een door de ontvanger uitgevaardigd dwangbevel moet aan de belastingschuldige worden betekend door een belastingdeurwaarder. In het wetsontwerp Invorderingswet was de mogelijkheid opgenomen een dwangbevel te betekenen door ter post bezorging in plaats van betekening door een belastingdeurwaarder. De betekening door ter post bezorging is door de Tweede Kamer niet overgenomen. Artikel 13 bepaalt dat betekening van een dwangbevel geschiedt overeenkomstig de regels van het Wetboek van Burgerlijke Rechtsvordering. De tenuitvoerlegging van een dwangbevel begint met een bevel tot betaling binnen twee dagen. Indien de belastingschuldige niet betaalt, wordt het dwangbevel ten uitvoer gelegd overeenkomstig de regels van het Wetboek van Burgerlijke Rechtsvordering met betrekking tot de tenuitvoerlegging van vonnissen en authentieke akten (artikel 14).

In artikel 15 is bepaald dat in de gevallen genoemd in artikel 10 de invordering versneld kan plaatsvinden. Een belastingschuldige kan tegen de tenuitvoerlegging van een dwangbevel in verzet komen bij de rechtbank. Het verzet schorst de tenuitvoerlegging van het dwangbevel voor zover deze door het verzet wordt bestreden. Het verzet kan niet gegrond zijn op de stelling dat het aanslagbiljet of de aanmaning niet is verzonden of dat de belastingaanslag ten onrechte of tot een te hoog bedrag is vastgesteld (artikel 17).

\section{Open systeem}

In de nieuwe wet is in artikel 3 , lid 2 gekozen voor het open systeem, dit in tegenstelling tot het gesloten systeem in de oude wet. Het gesloten systeem hield in dat de ontvanger uitsluitend de middelen tot invordering mocht gebruiken die hem uitdrukkelijk in de invorderingswet ter 


\section{MAB}

beschikking waren gesteld. In het open systeem heeft de ontvanger naast de bijzondere bevoegdheden in de invorderingswet dezelfde bevoegdheden die een schuldeiser op grond van enige andere wettelijke bepaling - de algemene bevoegdheden - heeft. De bijzondere bevoegdheden zijn:

- het recht van voorrang en het bodemrecht;

- het recht van verrekening;

- de aansprakelijkheidsbepalingen;

- de informatieverplichtingen ten behoeve van de invordering.

Het open systeem biedt de ontvanger ook de mogelijkheid inning van de belastingschuld via de civielrechtelijke weg te bewerkstelligen.

Onder de oude wet miste de ontvanger de bevoegdheid het faillissement van een belastingschuldige aan te vragen. Aangenomen werd dat de ontvanger geen conservatoir beslag mocht leggen. Onduidelijk was voorts of de ontvanger de actio pauliana - de mogelijkheid voor een schuldeiser om de nietigheid in te roepen van door een schuldenaar onverplicht verrichte handelingen, waardoor de schuldeisers worden benadeeld - kon toepassen en of hij cessies tot zekerheid kon bedingen en ontvangen. Onder de nieuwe wet is de ontvanger in het bezit van deze algemene bevoegdheden. In paragraaf 1 , sub 5 Leidraad zijn de algemene uitgangspunten van het invorderingsbeleid verwoord. Indien de invordering op verschillende wijzen kan geschieden geldt als uitgangspunt dat de voor de fiscus eenvoudigste en minst kostbare wijze de voorkeur verdient, tenzij het belang van de invordering daardoor zou worden geschaad. Daarnaast geldt als uitgangspunt dat derden niet onnodig bij de invordering mogen worden betrokken. Een belastingschuldige kan zich op grond van de beginselen van behoorlijk bestuur op het in de Leidraad gestelde beroepen. De uitleg van bekendgemaakte beleidsregels kan in cassatie getoetst worden.

\section{Fiscaal voorrecht en bodemrecht}

In de nieuwe wet heeft de ontvanger zijn recht van voorrang op andere crediteuren - met uitzonde- ring van de gerechtskosten van artikel 1185, sub 1 en 1195, sub 1 Burgerlijk Wetboek en het recht van hypotheek - en het bodemrecht voorlopig behouden. In artikel 21 is bepaald dat de ontvanger het recht van voorrang heeft op al de roerende en onroerende goederen van de belastingschuldige. Het fiscale voorrecht geldt gedurende de gehele periode waarin een belastingaanslag kan worden ingevorderd. Het recht van voorrang vervalt op grond van artikel 27 na vijf jaren. Deze termijn was onder de oude wet twee jaren. In afdeling 1 , paragraaf 1 , punt 4 Leidraad wordt als beleid uitgedragen dat de fiscus zoveel mogelijk het geldend maken van het voorrecht boven pand zal beperken.

Het bodemrecht, neergelegd in artikel 22, geeft de ontvanger de mogelijkheid zich te verhalen op bepaalde roerende goederen van derden die zich tijdens een beslaglegging op de bodem van de belastingschuldige bevinden. Het bodemrecht is beperkt tot naheffingsaanslagen in

- de loonbelasting;

- de omzetbelasting;

- de bijzondere verbruiksbelasting;

- de dividendbelasting;

- de kansspelbelasting;

- de assurantiebelasting;

- de beursbelasting.

De mogelijkheid van het bodemrecht ter zake van bijvoorbeeld een aanslag inkomstenbelasting of een aanslag vennootschapsbelasting is vervallen. Derden kunnen binnen zeven dagen na de beslaglegging bij de ontvanger een bezwaarschrift indienen gericht aan de directeur. Zij kunnen ook verzet plegen bij de burgerlijke rechter. Getoetst kan dan alleen worden of aan de voorwaarden voor toepassing van het bodemrecht is voldaan.

Het fiscaal voorrecht en het bodemrecht zijn reeds lange tijd onderwerp van discussie. In artikel 70 is een zogenaamde 'horizonbepaling' opgenomen, die bepaalt dat het bodemrecht op 1 januari 1993 vervalt, tenzij er eerder een wetsvoorstel over de definitieve regeling van het bodemrecht is ingediend. Een inter-departementale werkgroep heeft de opdracht gekregen de 


\section{MAB}

niet in het Burgerlijk Wetboek geregelde voorrechten en het bodemrecht te bestuderen, teneinde indiening van een wetsvoorstel mogelijk te maken. Het rapport van de werkgroep is op 4 juli 1990 aan de Tweede Kamer aangeboden. De werkgroep adviseert het bodemrecht met een aantal wijzigingen te handhaven en mede te betrekken op de sociale verzekeringspremies. Verder bepleit de werkgroep het bestaande voorrecht dat de fiscus en de bedrijfsverenigingen hebben ten opzichte van andere crediteuren in rangorde te verlagen en de gemeentelijke en provinciale belastingen wat de bevoorrechting betreft gelijk te stellen met het fiscale voorrecht. Een aantal voorrechten verbonden aan vorderingen van de overheid behoren volgens de werkgroep te vervallen. De ministerraad heeft met de conclusies van de werkgroep ingestemd.

\section{Verrekening}

In artikel 24 zijn de fiscale verrekeningsregels opgenomen. Bepaald is - dit is nieuw - dat schuldvergelijking op grond van de artikelen 1461 tot en met 1471 Burgerlijk Wetboek uitgesloten is. Gehandhaafd is de schuldvergelijking uit de artikelen 53 tot en met 56, 234 en 235 Faillissementswet. De ontvanger is bevoegd aan hem uit te betalen en van hem te innen bedragen met elkaar te verrekenen. Indien de belastingschuldige om verrekening verzoekt is de ontvanger hiertoe verplicht. Binnen een fiscale eenheid voor de vennootschapsbelasting geldt de verrekeningsmogelijkheid voor alle tot de eenheid behorende vennootschappen. Verrekening is mogelijk vanaf het moment van dagtekening van het aanslagbiljet of van de beschikking in de zin van de Algemene wet inzake de douane en de accijnzen. Verrekening is dus al mogelijk vóór de betalingstermijn is verlopen, tenzij de afwijkende regeling voor bepaalde voorlopige aanslagen over het lopende jaar van artikel 9 , lid 4 van toepassing is.

Artikel 24 geldt voor alle belastingen en heffingen waarvan de invordering aan de ontvanger is overgedragen. In geval van overdracht van een vordering op de ontvanger aan een derde - cessie -, waar de ontvanger mee heeft ingestemd, is verre- kening niet mogelijk. Indien de ontvanger besluit om zijn instemming met cessie van een vordering op hem te weigeren, kan de belastingschuldige daartegen binnen zeven dagen een bezwaarschrift bij de directeur indienen.

\section{Aansprakelijkheidsbepalingen}

De aansprakelijkheidsbepalingen zijn in hoofdstuk VI opgenomen. Door middel van een aansprakelijkstelling kan de ontvanger de vordering van een belastingschuldige op een derde verhalen. Voor een groot deel gaat het om het bijeenbrengen van de volgende - reeds bestaande bepalingen:

- de inlenersaansprakelijkheid voor de loonbelasting en de omzetbelasting (artikel 34);

- de ketenaansprakelijkheid van de aannemer voor de loonbelasting (artikel 35);

- de bestuurdersaansprakelijkheid voor de loonbelasting en de omzetbelasting (artikel 36);

- de aansprakelijkheid voor de ten onrechte niet ingehouden loonbelasting en kansspelbelasting (artikel 38);

- de aansprakelijkheid van gevoegde dochtervennootschappen in een fiscale eenheid vennootschapsbelasting voor de vennootschapsbelastingschulden van de moedervennootschap (artikel 39);

- de aansprakelijkheid voor de vennootschapsbelasting en dividendbelasting van een lichaam waarvan de plaats van vestiging buiten Nederland is gebracht (artikel 41);

- de aansprakelijkheid voor de overdrachtsbelasting (artikel 42);

- de aansprakelijkheid voor de op grond van artikel 5 Wet op de inkomstenbelasting 1964 aan derden toegerekende inkomensbestanddelen (artikel 44);

- de aansprakelijkheid voor de op grond van artikel 5 Wet op de vermogensbelasting 1964 aan echtgenoten toegerekende bezittingen en schulden (artikel 45);

- de aansprakelijkheid voor het recht van successie, het recht van overgang en het schenkingsrecht (artikelen 46, 47 en 48).

Nieuw is dat de ontvanger in alle gevallen aan- 


\section{MAB}

sprakelijk stelt. Voorheen was dat soms de inspecteur. De aansprakelijkstelling geldt op grond van artikel 32, lid 2 niet voor in de belastingaanslag begrepen verhogingen en van rente en kosten, tenzij het belopen ervan aan de aansprakelijke te wijten is. Nieuw is ook:

- In artikel 32, lid 1 is uitdrukkelijk bepaald dat elke wettelijke aansprakelijkheidsregeling die niet in deze wet is opgenomen, van kracht blijt, zoals de aansprakelijkheid van echtgenoten en de aansprakelijkheid van vennoten in een vennootschap onder firma.

- De aansprakelijkheid van iedere bestuurder van een lichaam zonder rechtspersoonlijkheid of een niet volledig rechtsbevoegd lichaam betreft nu alle rijksbelastingen. Ook de leider van een vaste inrichting, de vaste vertegenwoordiger en de vereffenaar van een ontbonden lichaam zijn aansprakelijk voor alle rijksbelastingen (artikel 33 en 37).

- In artikel 40 is een bepaling opgenomen die het leeghalen van vennootschappen tracht tegen te gaan. Vervreemders van aandelen die tot een aanmerkelijk belang behoren en van deelnemingen in de zin van artikel 13 vennootschapsbelasting zijn aansprakelijk voor (een evenredig deel van) de door de vennootschap verschuldigde vennootschapsbelasting, zowel ter zake van de gehele c.q. nagenoeg gehele staking van de onderneming, als van de voorafgaande jaren. Het betreft vervreemdingen, die in het jaar van (nagenoeg geheel) staken of één van de drie daaraan voorafgaande jaren hebben plaatsgevonden. Aansprakelijkstelling is slechts mogelijk indien goederen van de vennootschap zijn verduisterd en de vervreemder dit wist dan wel behoorde te weten.

- Nieuw is artikel 43 , lid 2. In artikel 43 lid 1 is bepaald dat natuurlijke personen en lichamen die tot een fiscale eenheid in de zin van de omzetbelasting behoren op grond van artikel 43 hoofdelijk aansprakelijk zijn voor de volledige door de fiscale eenheid verschuldigde omzetbelasting. In lid 2 is opgenomen dat de ontvanger een vermindering of teruggaaf kan voldoen aan één van de natuurlijke personen of lichamen van de fiscale eenheid omzetbelasting.
In hoofdstuk VI, afdeling 1, paragraaf 1 Leidraad staat vermeld dat de ontvanger zich in beginsel eerst zal verhalen op vermogensbestanddelen van de belastingplichtige voordat hij overgaat tot uitwinning van de vermogensbestanddelen van de aansprakelijkgestelde.

\section{Informatieverplichtingen}

Nieuw is hoofdstuk VII waarin de bepalingen zijn opgenomen waaraan de ontvanger de bevoegdheid kan ontlenen in het kader van de invordering gegevens en inlichtingen, alsmede inzage in boeken en bescheiden te vragen. Deze bepalingen stemmen grotendeels overeen met wat in de Algemene wet inzake rijksbelastingen ter zake van de heffing is geregeld. In artikel 62 , lid 3 is bepaald dat bedienaren van de godsdienst, notarissen, advocaten, procureurs, geneeskundigen en apothekers met een beroep op hun eigen geheimhoudingsplicht het geven van informatie kunnen weigeren.

\section{Faillissement}

Een belangrijke wijziging in de nieuwe wet is dat de ontvanger nu bevoegd is het faillissement van een belastingschuldige aan te vragen. In hoofdstuk I, artikel 3, paragraaf 3 Leidraad wordt uiteengezet dat met de bevoegdheid om faillissement aan te vragen uiterst terughoudend moet worden omgegaan. De belastingschuldige moet in een toestand verkeren dat hij heeft opgehouden te betalen. Deze betalingsonmacht mag niet van korte duur zijn en de openstaande schuld moet niet binnen redelijke termijn op een andere manier kunnen worden ingevorderd. De aanslagen waarvoor het faillissement wordt aangevraagd moeten onherroepelijk vaststaan en materieel verschuldigd worden geacht. Ook moet er geen uitstel van betaling gelden voor de betreffende aanslagen. Voor iedere faillissementsaanvraag dient de ontvanger over een schriftelijke machtiging van het ministerie te beschikken. In de Leidraad wordt uitdrukkelijk bepaald dat elk dreigen met het aanvragen van een faillissement achterwege moet blijven zolang de ontvanger daartoe niet gemachtigd is. 


\section{MAB}

\section{Belastingdeurwaarder}

In artikel 4 is bepaald dat tot het verrichten van de bij of krachtens de wet aan een deurwaarder opgedragen werkzaamheden uitsluitend een belastingdeurwaarder bevoegd is. In hoofdstuk I, artikel 4, paragraaf 1, sub 1 Leidraad staat dat de belastingdeurwaarder bevoegd is tot het uitbrengen van alle exploiten en het treffen van alle invorderingsmaatregelen die rechtstreeks verband houden met de invorderingstaak van de ontvanger. Dit betekent dat de belastingdeurwaarder ook bevoegd is tot die werkzaamheden die voortvloeien uit de invordering langs civiele weg waartoe de ontvanger volgens het open systeem gerechtigd is, als ook tot die werkzaamheden die verricht moeten worden wanneer de ontvanger zelfstandig eisend en verwerend in rechte optreedt.

\section{Uitstel van betaling}

Op grond van artikel 25 kan de ontvanger onder door hem te stellen voorwaarden aan een belastingschuldige uitstel van betaling verlenen. In hoofdstuk IV, afdeling 3 Leidraad zijn de algemene uitgangspunten van het uitstelbeleid verwoord.

\section{Kwijtschelding}

In artikel 26 wordt de mogelijkheid van gehele of gedeeltelijke kwijtschelding van belasting aangegeven. In hoofdstuk IV, afdeling 3 Leidraad is het kwijtscheldingsbeleid uiteengezet.

\section{Verjaring}

In artikel 27 is bepaald dat de verjaringstermijn van het recht tot dwanginvordering en het recht van verrekening van een belastingaanslag vijf jaren bedraagt. Deze termijn was onder de oude wet 3 jaren.

\section{Rente}

In hoofdstuk $V$ wordt het onderwerp rente behandeld. Enerzijds wordt een belastingschuldige, indien hij een belastingaanslag niet of niet volledig betaalt binnen de daarvoor gestelde termijn, rente - invorderingsrente - in rekening gebracht. Anderzijds wordt aan de belastingschuldige invorderingsrente vergoed in het geval waarin bij vermindering van de belastingaanslag het bedrag van de vermindering meer beloopt dan het op de belastingaanslag nog openstaande bedrag (artikel 28). Het percentage van de invorderingsrente is gelijk aan dat van de wettelijke rente (artikel 29).

\section{Bestemming van de betaling}

In hoofdstuk I, artikel 7, paragraaf 1 Leidraad staat dat betalingen waarvan de bestemming is aangegeven, worden afgeboekt oveenkomstig de bedoeling van de betaler. Wanneer de betaling is gedaan zonder aangegeven bestemming stelt de ontvanger de betaler schriftelijk in de gelegenheid alsnog een bestemming aan te geven. Indien er geen bestemming wordt aangegeven, vindt afboeking plaats op de oudst openstaande belastingaanslag.

\section{Sancties}

In hoofdstuk VIII zijn de strafrechtelijke bepalingen opgenomen. In artikel 64 wordt het onjuist of onvolledig verstrekken van inlichtingen of gegevens en het geen, valse of vervalste boeken of andere bescheiden ter inzage verstrekken als overtreding strafbaar gesteld en als misdrijf indien er sprake is van opzet. In artikel 65 is bepaald dat geen strafvervolging wordt ingesteld indien uit vrije wil alsnog juiste en volledige inlichtingen of gegevens worden verstrekt, mits het niet tijdig verstrekken niet van invloed is geweest op de verhaalsmogelijkheden.

\section{Conclusie}

De Invorderingswet 1990 wijkt op een aantal punten sterk af van de Invorderingswet 1845. Er is gekozen voor het open systeem, in tegenstelling tot het gesloten systeem in de oude wet. De ontvanger heeft de bevoegdheid gekregen het faillissement van een belastingschuldige aan te vragen. De ontvanger heeft het ter discussie staande 


\section{MAB}

recht van voorrang op andere crediteuren en het bodemrecht voorlopig behouden, zij het dat het bodemrecht niet meer geldt voor een aanslag inkomstenbelasting of een aanslag vennootschapsbelasting. Het recht van voorrang vervalt na vijf jaren, in plaats van twee jaren. De ontvanger heeft de mogelijkheid niet in te stemmen met een cessie van een belastingrestitutie. $\mathrm{Er}$ is een aansprakelijkheidsbepaling opgenomen die het leeghalen van vennootschappen tracht tegen te gaan. Nieuw is ook dat er informatieverplichtingen ten behoeve van de ontvanger zijn opgenomen. Op het niet nakomen hiervan zijn sancties gesteld. 